\title{
PENGARUH PEMBINAAN DAN DISIPLIN GURU OLAHRAGA TERHADAP PENGEMBANGAN EKSTRAKURIKULER BOLA VOLI
}

\author{
Alam Hadi Kosasih \\ Dosen STKIP Subang
}

\begin{abstract}
The research entitled The Influence of Coaching And Discipline of Teacher Exercise on Vitar Ball Extracurricular Development is aimed to find out whether there is an influence between "Development and discipline of Sports Teachers towards Vocational Ball Extracurricular Development in SMP Negeri 2 Jatinangor Sumedang Regency." The research conducted is quantitative research. The sample used amounted to 30 people. Determination of sample using random sampling technique. Prior to data analysis, normality and homogeneity tests were first conducted to determine whether the data showed normal and homogeneous. Data analysis technique used is f-test. From the calculation of regression analysis $X 1$ and $X 2$ to $Y$ in the regression coefficient value of Fcount $=6.37>$ Ftable $=4.21$ can be concluded that $\mathrm{HO}$ rejected and $\mathrm{Ha}$ accepted, thus in penelitin conducted there is a significant influence between Development and Teacher Discipline against Development of Extracurricular Voly Ball at SMP Negeri 2 Jatinangaor Sumedang District.
\end{abstract}

Keywords: Coaching, Teacher Discipline, Extracurricular Volley Ball.

\begin{abstract}
ABSTRAK
Penelitian yang berjudul Pengaruh Pembinaan Dan Disiplin Guru Olahragaterhadap Pengembangan Ekstrakurikuler Voli Ball dilaksanakan bertujuan untuk mengetahui apakah ada pengaruh antara "Pembinaan dan disiplin Guru Olahraga terhadap Pengembangan Ekstrakurikuler Voli Ball di SMP Negeri 2 Jatinangor Kabupaten Sumedang." Penelitian yang dilaksanakan merupakan penelitian kuantitatif. Sampel yang digunakan berjumlah 30 orang. Penentuan sampel menggunakan teknik random sampling. Sebelum dilakukan analisis data, terlebih dahulu dilakukan uji normalitas dan homogenitas untuk mengetahui apakah data menunjukan normal dan homogen. Teknik analisis data yang digunakan adalah uji-f. Dari hasil perhitungan analisis regresi $X 1$ dan $X 2$ terhadap $Y$ di dapat nilai koofesien regresi Fhitung = 6,37 > Ftabel=4.21 dapat di simpulkan bahwa $\mathrm{HO}$ ditolak dan Ha diterima, dengan demikian dalam penelitin yang dilaksanakan terdapat pengaruh yang signifikan antara Pembinaan dan Disiplin Guru terhadap Pengembangan Ekstrakulikuler Voly Ball di SMP Negeri 2 Jatinangaor Kabupaten Sumedang.
\end{abstract}

Kata Kunci: Pembinaan, Disiplin Guru, Ekstrakurikuler Voli Ball. 


\section{A. Pendahuluan}

Olahraga ekstrakurikuler di sekolah bermanfaat untuk memupuk kebiasaan siswa dalam kedisiplin, dan mengisi waktu luang dengan kegiatan-kegiatan yang positif. Mendikbud $\mathrm{Ri}$ No. 054/U/1993 menjelaskan sebagai berikut :

Kegiatan ekstrakurikuler adalah kegiatan yang diselenggarakan di luar jam pelajaran yang tercantum dalam susunan program sesuai dengan keadaan dan kebutuhan sekolah. Kegiatan ini berupa kegiatan pengayaan dan perbaikan yang berkaitan dengan program kurikuler.

1. Merangsang pertumbuhan dan perkembangan jasmani yang serasi, selaras dan seimbang

2. Meningkatkan perkembangan dan sikap disiplin, mental, sosial, dan emosional yang serasi, selaras dan seimbang

3. Memberikan kemampuan untuk dapat menjelaskan manfaat pendidikan jasmani dan kesehatan serta hasrat bergerak.
4. Meningkatkan perkembangan dan aktivitas sistem peredaran darah, pencernaan, pernapasan dan syaraf.

5. Memberikan kemampuan untuk memelihara dan meningkatkan kesegaran jasmani dan kesehatan.

6. Terbentuk sikap prilaku seperti : disiplin, kejujuran, kerjasama, mengikuti peraturan dan ketentuan yang berlaku.

7. Menyenangi aktivitas jasmani yang dapat dipakai untuk mengisi waktu luang serta kebiasaan hidup sehat.

Ekstrakurikuler merupakan bagian integral dari pendidikan jasmani, olahraga dan kesehatan bertujuan untuk mengembangkan aspek kebugaran jasmani, keterampilan gerak, keterampilan berfikir kritis, keterampilan sosial, penalaran, stabilitas emosional, tindakan moral, aspek pola hidup sehat dan pengenalan lingkungan bersih melalui aktivitas permainan bola voli yang direncanakan secara sistematis dalam rangka mencapai prestasi yang tinggi.

Ekstrakurikuler bola voli sebagai suatu proses pembinaan 
prestasi non akademik,

ekstrakurikuler bola voli yang diajarkan di sekolah memiliki peranan sangat penting, yaitu memberikan kesempatan kepada peserta didik untuk terlibat langsung dalam berbagai pengalaman belajar melalui ekstrakurikuler bola voli. Pembekalan pengalaman belajar itu diarahkan untuk membina prestasi yang tinggi, pertumbuhan fisik dan pengembangan psikis yang lebih baik, sekaligus membentuk pola hidup sehat dan bugar sepanjang hayat.

Berdasarkan permasalahan tersebut peran dari perangkat sekolah sebagai penyelenggara program ekstrakurikuler sangat penting dalam mendorong minat dan motivasi siswa untuk mau aktif mengikuti kegiatan ekstrakurikuler di sekolah. Pelaksanaan programprogram kegiatan ekstrakurikuler hendaknya dikendalikan untuk pencapaian tujuan-tujuan yang telah diterapkan dan kontribusinya terhadap perwujudan visi sekolah. Dari setiap pelaksanaan program kegiatan ekstrakurikuler hendaknya diusahakan suasana yang kondusif, tidak terlalu membebani siswa dan tidak merugikan aktivitas kurikuler sekolah.

Dalam hal ini guru merupakan salah satu pendukung keberhasilan dalam

penyelenggaraan pendidikan. Arti guru menurut Supriyadi (2011:11) yakni guru merupakan "Pendidik profesional dengan tugas utama mendidik, mengajar, membimbing, mengarahkan, melatih, menilai, dan mengevaluasi peserta didik pada jalur pendidikan formal yakni sekolah". Di samping itu, Borich (1990:67) menyebutkan bahwa "Perilaku mengajar guru yang baik dalam proses belajar-mengajar di kelas dapat ditandai dengan adanya kemampuan penguasaan materi pelajaran, kemampuan penyampaian materi pelajaran, keterampilan pengelolaan kelas, kedisiplinan, antusiasme, kepedulian, dan keramahan guru terhadap siswa".

Berdasarkan pendapat di atas dapat disimpulkan bahwa untuk menjadi guru yang baik perlu memiliki kemampuan dalam 
membina para peserta didik serta mimiliki kedisiplinan yang tinggi agar dapat menjadi contoh yang baik kepada para peserta didik.

Pembinaan adalah penyempurnaan dan perbaikan yang dilakukan oleh pembina yang dimana disini yang menjadi pembina adalah guru secara berdaya guna, sehingga apa yang diharapakan dari pengelola kegiatan ekstra kurikuler yakni guru pengelola kegiatan ekstra kurikuler mendapatkan hasil yang lebih baik dari yang kemarin bagi sekolah. Pembinaan guru dapat dilakukan dengan pemberian motivasi, bimbingan, pengarahan, dan evaluasi.

Melalui bimbingan dan pelatihan guru, kegiatan ekstrakurikuler dapat membentuk sikap positif terhadap kegiatan yang diikuti oleh para siswa. Berdasarkan Peraturan Menteri Pendidikan Nasional Republik Indonesia Nomor 39 Tahun 2008 tentang Pembinaan kesiswaan.

Sedangkan kedisiplinan guru diartikan sebagai sikap mental yang mengandung kerelaan mematuhi semua ketentuan, peraturan dan norma yang berlaku dalam menunaikan tugas dan taggung jawab. Dari pengertian tersebut dapat disimpulkan kedisiplinan guru adalah sikap penuh kerelaan dalam mematuhi semua aturan dan norma yang ada dalam menjalankan tugasnya sebagai bentuk tanggung jawabnya terhadap pendidikan anak didiknya. Karena bagaimana pun seorang guru atau tenaga kependidikan, merupakan cermin bagi anak didiknya dalam sikap atau teladan, dan sikap disiplin guru akan memberikan warna terhadap hasil pendidikan yang jauh lebih baik.

Berdasarkan uraian-uraian penjelasan di atas diharapkan melalui pembinaan dan disiplin guru olahraga dapat mengembangkan kegiatan ekstrakurikuler bola voli khususnya di lingkungan SMP Negeri 2 Jatinangor Kabupaten Sumedang.

Berdasarkan latar belakang penelitian di atas, penelitian merumuskan identifikasi masalah sebagai berikut:

1. Pembinaan guru di SMP Negeri 2 Jatinangor 
Kabupaten Sumedang belum opimal.

2. Disiplin guru olahraga di SMP Negeri 2 Jatinangor Kabupaten Sumedang masih rendah.

3. Perkembangan ekstrakurikuler Bola Voli di SMP Negeri 2 Jatinangor Kabupaten Sumedang masih sangat rendah.

\section{B. Metode Penelitian}

Metode adalah jalan yang dilalui atau yang ditempuh untuk mencapai suatu tujuan. Tujuan dari penelitian ini adalah untuk mengungkapkan,

menggambarkan, dan menyimpulkan hasil pemecahan masalah melalui cara-cara tertentu sesuai dengan prosedur penelitian. Metode penelitian yang penulis gunakan dalam penelitian ini adalah metode penelitian expos facto.

1. Penelitian ex post facto merupakan penelitian yang bertujuan menemukan penyebab yang memungkinkan perubahan perilaku, gejala atau fenomena yang disebabkan oleh suatu peristiwa, perilaku atau hal-hal yang menyebabkan perubahan pada variable bebas yang secara keseluruhan sudah terjadi.

2. Penelitian ex post facto secara metodis merupakan penelitian eksperimen yang juga menguji hipotesis tetapi tidak memberikan perlakuanperlakuan tertentu karena sesuatu sebab kurang etis untuk memberikan perlakuan atau memberikan manipulasi. Biasanya karena alasan etika manusiawi, atau gejala/peristiwa tersebut sudah terjadi dan ingin menelusuri faktor-faktor penyebabnya atau hal-hal yang mempengaruhinya.

3. Menurut Watson penelitian ex post facto bertujuan untuk mencari penyebab perubahan perilaku dengan studi komparasi secara partisipatif tentang perilaku yang muncul pada saat sekarang dan perilaku yang tidak muncul dari suatu kejadian setelah variable bebas terjadi. Sebagai contoh: akan menguji hipotesis bahwa perceraian dapat mengakibatkan penyimpangan perilaku anak- 
anak. Dalam situasi ini, kita tidak dapat mengeksperimenkan suatu keluarga untuk melakukan perceraian. Perceraian dalam hal ini merupakan variable bebas yang tidak dapat dimanipulasikan. Suatu hal yang tidak mungkin dilakukan berdasarkan pertimbangan kemanusiaan. Karena hal tersebut, penelitian dilakukan pada keluarga yang sedang mengalami perceraian..

4. Kerlinger (1993) mendefinisikan penelitian ex post facto adalah penemuan empiris yang dilakukan secara sistematis, peneliti tidak melakukan kontrol terhadap variable-variabel bebas karena manifestasinya sudah terjadi atau variable-variabel tersebut secara inheren tidak dapat dimanipulasi. Sebagai contoh: Seorang peneliti ingin mengetahui pengaruh merokok terhadap kemampuan menyerap oksigen dalam darah. Peneliti tidak mungkin melakukan eksperimen dengan menyuruh orang menghisap beberapa batang rokok dalam sehari untuk diketahui pengaruhnya terhadap kemampuan darah dalam mengikat oksigen.

5. Nana Syaodih Sukmadinata (2006: 55) menyatakan penelitian ekspos fakto (expost facto research) meneliti hubungan sebab akibat yang tidak dimanipulasi atau diberi perlakuan (dirancang dan dilaksanakan) oleh peneliti. Penelitian ekspos fakto dilakukan terhadap program, kegiatan yang telah berlangsung atau telah terjadi. Penelitian ekspos fakto tidak ada pengontrolan variabel dan biasannya tidak ada pra tes

Sehubungan dengan masalah yang ingin penulis ungkapkan yaitu tentang "Pengaruh pembinaan dan disiplin guru olahraga terhadap pengembangan ekstarkulikuler Bola Voli ", maka dalam penelitian ini penulis mengumpulkan data dari variable hubungan, pembinaan dan disiplin guru olahraga terhadap pengembangan ekstarkulikuler Bola Voli. Selanjutnya data yang terkumpul penulis susun, dan penulis jelaskan kemudian dianalisis. 


\section{Hasil Penelitian}

Penelitian

yang

dilaksanakan di lingkungan SMP Negeri 2 Jatinangor, dengan sampel penelitian siswa kelas IX yang berjumlah 30 orang yang di pilih secara acak dari jumlah populasi 124 siswa. Dengan karakteristik sampel sebagai berikut:

Tabel 1 Karakteristik Sampel

Penelitian

\begin{tabular}{|c|c|c|c|}
\hline Sekolah & Status Sampel & Jenis Kelamin & Jumlah \\
\hline $\begin{array}{c}\text { SMP Negeri } 2 \\
\text { Jatinangor }\end{array}$ & Siswa Kelas XI & Laki-laki & 17 \\
\cline { 3 - 4 } & Perempuan & 13 \\
\hline \multicolumn{2}{|l}{} & 30 \\
\hline
\end{tabular}

Setelah memperoleh data Pembinaan Dan Disiplin Guru Terhadap Pengembangan Ekstrakulikuler Voly Ball Di SMP Negeri 2 Jatinangaor Kabupaten Sumedang langkah selanjutnya adalah mengolah dan menganalisis data agar data tersebut memberikan suatu jawaban terhadap rumusan masalah yang diajukan. Oleh karena peneliti mendeskriptifsikan dan menyajikan berdasarkan hasil data yang diperoleh.

1. Deskripsi Variabel yang diteliti
Penelitian ini mencakup satu variable bebas dan satu variable terikat yaitu Pembinaan Dan Disiplin Guru Terhadap Pengembangan Ekstrakulikuler Voly Ball pada bagian ini akan disajikan hasil-hasil penelitian untuk setiap variable.

Tabel 1 Deskripsi Variabel

Pembinaan

\begin{tabular}{|l|c|}
\hline Jumlah Sampel & 30 \\
\hline Jumlah Butir & 10 \\
\hline Jumlah data & 1316 \\
\hline Rata-Rata & 43.87 \\
\hline Simpangan Baku & 3.17 \\
\hline Varian & 10.05 \\
\hline \multicolumn{2}{|c|}{ Variabel bebas X1 yaitu } \\
\hline
\end{tabular}

Pembinaan dalam penelitian ini mempunyai nilai data hasil analisis deskriptif, jumlah sampel 30 siswa, jumlah butir angket 10, jumlah data dari variabel X1 sebesar 1316, rata- rata sebesar 43,8 , simpangan sebesar 3,17. Deskriptis variabel di atas menjadi acuan untuk melanjutkan ke analisis staistika berikutnya, yaitu analisis regresi untuk menghitung besarnya pengaruh varibel $\mathrm{X}_{1}$ terhadap $\mathrm{Y}$.

2. Variabel Disiplin Guru 
Setelah dilakukan penelitian maka diperoleh perhitungan variabel disiplin guru sebagai berikut.

Tabel 2 Variabel Disiplin Guru

\begin{tabular}{|l|c|}
\hline Jumlah Sampel & 30 \\
\hline Jumlah Butir & 10 \\
\hline Jumlah data & 1193 \\
\hline Rata-Rata & 25.93 \\
\hline Simpangan Baku & 19.65 \\
\hline Varian & 386.06 \\
\hline \multicolumn{2}{|c|}{ Variabel bebas X2 yaitu }
\end{tabular}

Disiplin Guru dalam penelitian ini mempunyai nilai data hasil analisis deskriptif, jumlah sampel 30 siswa, jumlah butir angket 10 , jumlah data dari variabel $\mathrm{X} 2$ sebesar 1193, rata- rata sebesar 25,93, simpangan sebesar 19,64. Deskriptis variabel di atas menjadi acuan untuk melanjutkan ke analisis staistika berikutnya, yaitu analisis regresi untuk menghitung besarnya pengaruh varibel $X_{2}$ terhdap Y.

3. Variabel Ekstrakurikuler

Setelah dilakukan penelitian maka diperoleh perhitungan variable ekstrakulikuler sebagai berikut.

\begin{tabular}{|l|l|}
\hline Jumlah Sampel & 30 \\
\hline
\end{tabular}

\begin{tabular}{|l|l|}
\hline Jumlah Butir & 10 \\
\hline Jumlah data & 1206 \\
\hline Rata-Rata & 40.20 \\
\hline Simpangan Baku & 5.57 \\
\hline Varian & 31.06 \\
\hline \multicolumn{1}{|c|}{ Variabel terikat $\quad$ Y yaitu }
\end{tabular}

Ekstrakurikurer voly dalam penelitian ini mempunyai nilai data hasil analisis deskriptif, jumlah sampel 30 siswa, jumlah butir angket 10, jumlah data dari variabel $Y$ sebesar 1206, rata-rata sebesar 40,20, simpangan sebesar 5,57. Deskriptis variabel di atas menjadi acuan untuk melanjutkan ke analisis staistika berikutnya, yaitu analisis regresi untuk menghitung besarnya pengaruh varibel $X_{1}$ dan $X_{2}$ terhadap Y.

4. Hasil Pengujian Hipotesis

Hipotesis penelitin:

REGRESI X1 TERHADAP Y

\begin{tabular}{|c|c|c|c|}
\hline $\begin{array}{c}\text { Varia } \\
\text { bel }\end{array}$ & \multicolumn{2}{|c|}{ REGRESI } & $\begin{array}{c}\text { Ketera } \\
\text { ngan }\end{array}$ \\
\hline & F hitung & F tabel & \\
\hline $\begin{array}{c}\mathrm{X} \\
\text { Deng } \\
\text { an } \mathrm{Y}\end{array}$ & 6.04 & 4.20 & $\begin{array}{c}\text { Ada } \\
\text { Pengar } \\
\text { uh }\end{array}$ \\
\hline
\end{tabular}

REGRESI X2 TERHADAP Y 


\begin{tabular}{|c|c|c|c|}
\hline \multirow{2}{*}{$\begin{array}{c}\text { Varia } \\
\text { bel }\end{array}$} & \multicolumn{2}{|c|}{ REGRESI } & \multirow{2}{*}{$\begin{array}{c}\text { Keterang } \\
\text { an }\end{array}$} \\
\hline & F hitung & F tabel & \\
\hline $\begin{array}{c}\text { X2 } \\
\text { Deng } \\
\text { an } Y\end{array}$ & 4.43 & 4.20 & $\begin{array}{l}\text { Ada } \\
\text { Peng } \\
\text { aruh }\end{array}$ \\
\hline
\end{tabular}

5. Pembahasan

Berdasarkan

hasil

pengolahan dan analisis regresi data mengenai pengaruh

Pembinaan Dan Disiplin Guru Terhadap Pengembangan

Ekstrakulikuler Voly Ball Di SMP Negeri 2 Jatinangaor Kabupaten Sumedang, hasil perhitungan analisis regresi $\mathrm{X} 1$ terhadap $\mathrm{Y}$ di harga $a=7,72$ dan $b=0.74$ bertanda positif, analisis regresi ganda mencari pengaruh dari hubungan kausal dua variable bebas terhadap variable terikat, dapat nilai koofesien regresi Fhitung = 6,03 $>$ Ftabel=4.19 dapat di simpulkan bahwa $\mathrm{HO}$ ditolak dan $\mathrm{Ha}$ diterima, diketahui bahwa terdapat pengaruh yang signifikan antara Pembinaan Terhadap Pengembangan Ekstrakulikuler Voly Ball Di SMP Negeri 2 Jatinangaor Kabupaten Sumedang sebesar $F=6,03$.
Hasil perhitungan analisis regresi $\mathrm{X} 2$ terhadap $\mathrm{Y}$ di harga $\mathrm{a}=$ 55,15 dan $b=-0.37$ bertanda negatif, analisis regresi ganda mencari pengaruh dari hubungan kausal dua variable bebas terhadap variable terikat, dapat nilai koofesien regresi Fhitung= 4,43 > Ftabel= 4.19 dapat di simpulkan bahwa HO ditolak dan $\mathrm{Ha}$ diterima, diketahui bahwa terdapat pengaruh yang signifikan antara Disiplin Guru Terhadap Pengembangan Ekstrakulikuler Voly Ball Di SMP Negeri 2 Jatinangaor Kabupaten Sumedang sebesar $F=4,43$.

\section{Kesimpulan}

Berdasarkan

hasil pengolahan dan analisis regresi ganda data mengenai pengaruh Pembinaan Dan Disiplin Guru Terhadap Pengembangan Ekstrakulikuler Voly Ball Di SMP Negeri 2 Jatinangaor Kabupaten Sumedang, dapat ditarik kesimpulan sebagai berikut:

1. Pembinaan Guru dalam Pengembangan Ekstrakurikuler Bola Voli di SMP Negeri 2 Jatinangor sudah baik, hal tersebut dapat di lihat dari 
pengaruh yang sangat signifikan

dari Pembinaan Terhadap

Pengembangan Ekstrakulikuler

Voly Ball Di SMP Negeri 2

Jatinangaor

Kabupaten

Sumedang sebesar $\mathrm{F}=6,03$.

2. Disiplin

Guru dalam

pengembangan Ekstrakurikuler

Bola Voli di SMP Negeri 2 Jatinangor masih rendah, hal tersebut dapat dilihat dari pengaruh Disiplin Guru Terhadap Pengembangan Ekstrakulikuler Voly Ball Di SMP Negeri 2 Jatinangaor Kabupaten Sumedang sebesar $F=4,43$.

3. Pembinaan dan Disiplin Guru dalam Pengembangan Ekstrakurikuler Bola Voli di SMP 2 Jatinangor masih perlu di tingkatkan lagi, hal tersebut dapat di lihat dari pengaruh yang rendah antara Pembinaan Dan Disiplin Guru terhadap Pengembangan Ekstrakulikuler Voly Ball Di SMP Negeri 2 Jatinangaor Kabupaten Sumedang sebesar $\mathrm{F}=6,37$.

\section{DAFTAR PUSTAKA}

Ali, (2001) Instrumen Penelitian Karya Ilmiah Bandung: Rosda
Karya Andi Suhendro (2002) Dasar-Dasar Kepelatihan. Jakarta: Pusat Penerbitan Universitas Terbuka

Arikunto, Suharsimi. (2005). Dasar-dasar Evaluasi Pendidikan. Jakarta: Bumi Aksara.

Arikunto, Suharsini. (2006).

Prosedur Penelitian: Suatu Pendekatan Praktis. Jakarta: Rineka Cipta

Borich (1990) Observation skills for effective teaching New Jersey: Pearson Education

Cece Wijaya (1994) Kemampuan Dasar Guru Dalam Proses Belajar. Surabaya: Taman Bacaan

Djoko Pekik Irianto, (2002) Dasar Kepelatihan, Yogyakarta, FIK UNY Hadlari Nawawi (1996) Administrasi Pendidikan Jakarta : Gunung Agung Hamzah Ya'qub

Manajemen Kepemimpinan. Bandung : CV. Diponegoro Hari Setiono, (2009) Psikologi \& Pengembangan Diri Bandung; Grasindo 
Hasan Langgulung (1989) Filsafat

Pendidikan Fakultas Olahraga

UPI : Bandung

MENDIKBUD RI No. 054/U/1993

Tujuan Pendidikan Nasional

Jakarta. PT Rineka Cipta

Nasution (2005) Teknologi

Pendidikan Bumi Aksara

Ngalim Purwanto, (2000) Psikologi

Pendidikan, Bandung: PT

Remaja Rosdakarya

Oteng Sutisna, (1985) Administrasi

Pendidikan Bandung: Tarsito

Poerwadarminta, (1976) Kamus

Umum Bahasa Indonesia,

Jakarta: Balai Pustaka 